\title{
Vaccination with Dendritic Cells Pulsed with Peptides of Myelin Basic Protein Promotes Functional Recovery from Spinal Cord Injury
}

\author{
Ehud Hauben, ${ }^{1 \star}$ Amalia Gothilf, ${ }^{1 \star}$ Avi Cohen, ${ }^{2 \star}$ Oleg Butovsky, ${ }^{1}$ Uri Nevo, ${ }^{1,3}$ Igor Smirnov, ${ }^{2}$ Eti Yoles, ${ }^{2}$ \\ Solange Akselrod, ${ }^{3}$ and Michal Schwartz ${ }^{1}$ \\ ${ }^{1}$ Department of Neurobiology, The Weizmann Institute of Science, 76100 Rehovot, Israel, 2Proneuron Biotechnologies Limited, 74101 Ness-Ziona, Israel, \\ and ${ }^{3}$ School of Physics and Astronomy, Tel-Aviv University, 69978 Tel-Aviv, Israel
}

\begin{abstract}
Injury-induced self-destructive processes cause significant functional loss after incomplete spinal cord injury (SCI). Cellular elements of both the innate (macrophage) and the adaptive (T-cell) immune response can, if properly activated and controlled, promote posttraumatic regrowth and protection after SCI. Dendritic cells (DCs) trigger activation of effector and regulatory T-cells, providing a link between the functions of the innate and the adaptive immune systems. They also initiate and control the body's response to pathogenic agents and regulate immune responses to both foreign and self-antigens. Here we show that post-injury injection of bone marrow-derived DCs pulsed with encephalitogenic or nonencephalitogenic peptides derived from myelin basic protein, when administered (either systemically or locally by injection into the lesion site) up to $12 \mathrm{~d}$ after the injury, led to significant and pronounced recovery from severe incomplete SCI. No significant protection was seen in DC recipients deprived of mature T-cells. Flow cytometry, RT-PCR, and proliferation assays indicated that the DCs prepared and used here were mature and immunogenic. Taken together, the results suggest that the DC-mediated neuroprotection was achieved via the induction of a systemic T-cell-dependent immune response. Better preservation of neural tissue and diminished formation of cysts and scar tissue accompanied the improved functional recovery in DC-treated rats. The use of antigen-specific DCs may represent an effective way to obtain, via transient induction of an autoimmune response, the maximal benefit of immune-mediated repair and maintenance as well as protection against self-destructive compounds.
\end{abstract}

Key words: dendritic cells; autoimmunity; spinal cord injury (SCI); neuroprotection; neuroregeneration; inflammation; CNS trauma

\section{Introduction}

Spinal cord injury (SCI) often has a devastating outcome, which results not only from damage to directly injured neurons and poor regeneration but also from secondary damage to neighboring neurons that escaped the initial injury. These secondary events are caused mainly by the activity of injury-evoked destructive self-compounds, such as physiological substances in toxic excess of their normal levels or degradation products of selfcompounds (Faden, 1993). Recovery from SCI thus may be improved by preventing the spread of damage (i.e., by neuroprotection) and by promoting regrowth of damaged fibers for which the cell bodies are still viable (i.e., by regeneration) (Behrmann et al., 1994; Constantini and Young, 1994; Liu et al., 1994; Bazan et al., 1995; Basso et al., 1996; Beattie et al., 1997; Blesch and Tuszynski, 1997; Crowe et al., 1997; Bregman, 1998; Franzen et al., 1998;

Received May 8, 2003; revised June 30, 2003; accepted July 1, 2003.

This work was supported by Proneuron Biotechnologies Limited and in part by grants from The Glaucoma Research Foundation and The Alan Brown Foundation for Spinal Cord Injury awarded to M.S. M.S. holds the Maurice and Ilse Katz Professorial Chair in Neuroimmunology. We thank S. Smith for editing this manuscript and A. Sharoni for animal maintenance.

*E.H., A.G., and A.C. contributed equally to this work.

Correspondence should be addressed to Dr. Michal Schwartz, Department of Neurobiology, The Weizmann Institute of Science, 76100 Rehovot, Israel. E-mail: michal.schwartz@weizmann.ae.il.

Copyright $\odot 2003$ Society for Neuroscience $\quad$ 0270-6474/03/238808-12\$15.00/0
Bavetta et al., 1999; Bethea et al., 1999; Brewer et al., 1999; Moalem et al., 1999; Hauben et al., 2000a,b).

Studies over the last few years have provided evidence indicating that cell-mediated immunity, if properly controlled, plays a pivotal role in regrowth of the injured spinal cord and its protection from secondary degeneration (Hauben et al., 2000a,b, 2001a,b; Butovsky et al., 2001). A properly controlled immune response after spinal cord or optic nerve injury helps to protect spared fibers from secondary degeneration, rescue cell bodies of damaged fibers, and promote regrowth of severed axons. Passive or active immunization with T-cells specific to CNS-associated myelin antigens reduces secondary degeneration in rat and mouse models of optic nerve crush or spinal cord contusion (Moalem et al., 1999; Hauben et al., 2000a,b; Fisher et al., 2001; Yoles et al., 2001). Moreover, local implantation of macrophages activated by an autologous sciatic nerve in a completely transected spinal cord or optic nerve leads to regenerative growth with some recovery of function (Lazarov-Spiegler et al., 1996; Franzen et al., 1998; Rapalino et al., 1998).

A considerable body of literature assigns a key role to dendritic cells (DCs) in promoting and modulating immune responses in general and autoimmune responses in particular (Link et al., 2001; Knight et al., 2002). DCs are immune cells for which the principal function is antigen presentation. They have an extraordinary capacity to stimulate naive T-cells, control the quality of 
the T-cell response, and initiate primary immune responses (Mellman and Steinman, 2001). Their effects vary from conferring active autoimmunity to conferring immune tolerance, and they are capable of bringing about changes in T-cell polarization (Dittel et al., 1999; Xiao et al., 2001; Turley, 2002).

The diverse activities of DCs in immune regulation are a function of the diversity of DC subsets and lineages as well as the functional plasticity of DCs while still immature (Liu, 2001). The state of maturation of these cells, as well as their number and the context in which they are activated, determines the nature of the resulting immune response. Three distinct stages of DC differentiation were described recently, and it was suggested that tolerance is conferred when the DCs are partially or semi-mature, whereas only fully mature DCs are immunogenic. The decisive signal, which induces a T-cell-mediated immune response, seems to be the expression of CD86 (B7-2) and MHC class II (MHC-II) molecules concurrently with the release of proinflammatory cytokines, in particular interleukin (IL)-12, IL-6, and tumor necrosis factor $\alpha$ (TNF $\alpha$ ), from the DCs (Lutz and Schuler, 2002).

In the present study we injected DCs specifically pulsed with peptides of myelin basic protein (MBP) into the site of spinal cord contusion in rats. The purpose of this injection was to stimulate a well regulated primary immune response against antigens that are abundant at the injury site. We postulated that the use of DCs pulsed with an MBP peptide thus might provide a way to harness the immune system and exploit its functions for both protection and regeneration of the injured spinal tissue (Rapalino et al., 1998; Hauben et al., 2000a,b). In an attempt to obtain a beneficial outcome while reducing the risk of accompanying autoimmune disease, we also pulsed DCs with an altered peptide ligand, a segment of MBP (amino acids 87-99) in which the amino acid lysine in position 91 is replaced by alanine. This modified peptide (A91) has been shown to cross-react with the original encephalitogenic peptide, activating weak self-reacting T-cells and thereby inducing autoimmunity without the risk of inducing experimental autoimmune encephalomyelitis (EAE) (Gaur et al., 1997). When used as a vaccine in rats with injured spinal cords, it can evoke protective autoimmunity (Hauben et al., 2001a). The results showed that DCs pulsed with MBP-derived peptide, if injected either locally or systemically after SCI, promote recovery of locomotor activity. Recovery also was manifested by tissue preservation, measured morphologically and anatomically by magnetic resonance imaging (MRI).

\section{Materials and Methods}

Animals. Inbred adult Lewis or Sprague Dawley (SPD) rats (10-12 weeks old, 200-250 gm) were supplied by the Animal Breeding Center of The Weizmann Institute of Science (Rehovot, Israel). Rats were housed in a light- and temperature-controlled room and were matched for age in each experiment. All animals were handled according to the guidelines of National Institutes of Health and The Weizmann Institute of Science for the management of laboratory animals.

Spinal cord injury. Rats were anesthetized by intramuscular injection of Rompun (xylazine, $10 \mathrm{mg} / \mathrm{kg}$; Vitamed Pharmaceutical, Benyamina, Israel) and Vetalar (ketamine, $50 \mathrm{mg} / \mathrm{kg}$; Fort Dodge Laboratories, Fort Dodge, IA), and their spinal cords were exposed by laminectomy at the level of T8. At $1 \mathrm{hr}$ after the induction of anesthesia we dropped a $10 \mathrm{gm}$ rod onto the laminectomized cord from a height of $50 \mathrm{~mm}$ (defined as a "severe" injury), using the NYU impactor (first developed at New York University), a device shown to inflict a well calibrated contusive injury of the spinal cord (Basso et al., 1996; Young, 1996; Hauben et al., 2000a,b).

Antigens. Modified (nonencephalitogenic) MBP peptides were derived from an encephalitogenic peptide, amino acids 87-99 of MBP, by replac- ing the lysine residue 91 with alanine (A91; synthesized at the Weizmann Institute of Science). All peptides used in the study had a purity of $>95 \%$ as confirmed by reverse-phase HPLC. Ovalbumin was purchased from Sigma-Aldrich (Rehovot, Israel).

Preparation of rat DCs. DCs were generated from bone marrow by a previously described method (Talmor et al., 1998; Lutz et al., 1999), with some modifications. Femurs and tibias were removed from dead mature male SPD rats (7-10 weeks old), stripped of muscle and connective tissue, placed in $70 \%$ ethanol for 3 min for disinfection, and then washed with PBS. Both ends of the bones were cut with scissors, and the marrow was flushed out with calcium-free and magnesium-free PBS, using a syringe with a 23-gauge needle. Cell aggregates were broken down by vigorous pipetting. Red blood cells were lysed with ACK buffer [containing (in mM): $150 \mathrm{NH}_{4} \mathrm{Cl}, 10 \mathrm{KHCO}_{3}, 0.1 \mathrm{Na}_{2}$ EDTA, pH 7.2-7.4]. Bone marrow cells were counted and plated at $2-5 \times 10^{6}$ cells $/ \mathrm{ml}$ in a $250 \mathrm{ml}$ flask (total $15 \mathrm{ml}$ ). The cells were grown in DMEM supplemented with $100 \mu \mathrm{g} / \mathrm{ml}$ penicillin and streptomycin, $2 \mathrm{mM}$ L-glutamine, $50 \mu \mathrm{M}$ $\beta$-mercaptoethanol, $1 \mathrm{~mm}$ pyruvate, 1:100 nonessential amino acids, and $10 \%$ heat-inactivated and filtered fetal calf serum (referred to hereafter as DC medium). The cytokines recombinant murine granulocyte macrophage colony-stimulating factor (rmGM-CSF, PeproTech, Rocky Hill, $\mathrm{NJ}$ ) and recombinant murine interleukin 4 (rmIL-4, PeproTech), both at $20 \mathrm{ng} / \mathrm{ml}$, were added on day 0 . On days 2 and 4 the culture medium was replaced with DC medium supplemented with cytokines, and the floating cells were discarded. On day 7 the cells were collected with a cell scraper (Sarstedt, Newton, NC) for adherent cells and centrifuged, and the pellet was resuspended in fresh DC medium (without added cytokines; $2 \times 10^{6}$ cells per $\left.\mathrm{ml}\right)$ containing the specific antigen $(20 \mu \mathrm{g} / \mathrm{ml})$. The cells were pulsed (i.e., incubated for $2 \mathrm{hr}$ with the antigen), washed with fresh DC medium, and kept on ice until injected. Just before injection the cells were centrifuged and resuspended in PBS $\left(5 \times 10^{5}\right.$ cells in $5 \mu$ of PBS for local injection; $1 \times 10^{6}$ cells in $1 \mathrm{ml}$ of PBS for intravenous injection; $2 \times 10^{6}$ cells in $1 \mathrm{ml}$ of PBS for subcutaneous injection). For local injection the cells were loaded into a Hamilton syringe and injected into the spinal cord at the site of injury. For subcutaneous injection the cells were injected in the neck area at two injection sites ( $0.5 \mathrm{ml}$ each). For intravenous injection the cells were injected into the tail vein.

Reverse transcription-PCR. Total RNA was extracted by using TRI reagent. For the first-strand cDNA synthesis reaction, RNA was incubated at $65^{\circ} \mathrm{C}$ for $5 \mathrm{~min}$, chilled on ice, and then reverse-transcribed in the presence of oligo-dT primer plus (in $\mathrm{mm}$ ) 50 Tris- $\mathrm{HCl}, \mathrm{pH} 8.3,75 \mathrm{KCl}, 3$ $\mathrm{MgCl}_{2}, 20$ DTT, $0.5 \mathrm{dNTP}$ mixture, and $200 \mathrm{U}$ of SuperScript II RNase Reverse Transcriptase (Invitrogen, San Diego, CA) at $42^{\circ} \mathrm{C}$ for $1 \mathrm{hr}$. The generated cDNA was amplified with $0.6 \mathrm{U}$ of DyNAzyme II DNA polymerase (Finnzymes Oy, Rihitontuntie, Finland) in the presence of 50-70 pmol of primers plus (in mM) $0.1 \mathrm{dNTP}$ mixture, 10 Tris- $\mathrm{HCl}, \mathrm{pH} 8.8,1.5$ $\mathrm{MgCl}_{2}, 50 \mathrm{KCl}$, and $0.1 \%$ Triton X-100. The cycling conditions were 30 sec at $94^{\circ} \mathrm{C}$ for denaturation, $1 \mathrm{~min}$ at $60^{\circ} \mathrm{C}$ for annealing, $2 \mathrm{~min}$ at $72^{\circ} \mathrm{C}$ for extension, and $7 \mathrm{~min}$ at $72^{\circ} \mathrm{C}$ after the last cycle. cDNA samples were amplified by 24 cycles for L-19, 34 cycles for IL-6, 33 cycles for TNF- $\alpha$, and 34 cycles for IL-12 p-40. PCR products were visualized after electrophoresis on $1.5 \%$ agarose gels by staining with ethidium bromide. The following primers were used: L-19, 5'CTGAAGGTCAAAGGGAATGTG and 5'-GGACAGAGTCTTGATGATCTC; IL-6, 5' -ACTGCCTTCCCTACTTCAC and 5'-GTATTGCTCTGAATGACTCTG; TNF $\alpha, 5^{\prime}$ AGGAGGCGCTCCCCAAAAAGATGGG and $5^{\prime}$-GTACATGGGCTCATACCAGTTG; IL-12, 5' -AGATGACATCACCTGGACCT and 5' CTTTGGTTCAGTGTGACCTTC.

Fluorescence-activated cell sorter analysis. Bone marrow-derived cultured DCs $\left(5 \times 10^{5}\right)$ were stained with FITC-conjugated CD86 antibodies (anti-B7-2, mouse IgG1k, PharMingen, San Diego, CA), PEconjugated OX6 antibodies (anti-MHC-II mouse IgG1k, PharMingen), FITC-conjugated ED-1 (Serotec, Oxford, UK), FITC-conjugated CD45RA antibodies (PharMingen), and their control antibodies mouse IgG1 conjugated to FITC (Serotec) and mouse IgG1 conjugated to PE (PharMingen). The cells were incubated in $100 \mu$ l of PBS containing 2\% normal mouse serum and the diluted specific antibodies at $4^{\circ} \mathrm{C}$ for 30 $\mathrm{min}$. Cells were washed with $4 \mathrm{ml}$ of PBS and resuspended in $400 \mu \mathrm{l}$ of $0.1 \%$ paraformaldehyde. Samples were analyzed with a FACScan (fluo- 
rescence-activated cell sorter; Becton Dickinson, Heidelberg, Germany). Cells were stained for ED-1 after they had been fixed and permeabilized by using Leucoperm reagents (Serotec) according to the manufacturer's instructions.

Experimental protocol for DC administration. Bone marrow-derived cultured DCs were pulsed with MBP peptide 87-99, MBP-derived altered peptide A91, or ovalbumin $(20 \mu \mathrm{g} / \mathrm{ml})$ for $2 \mathrm{hr}$, washed with PBS, and adjusted to the appropriate number and volume just before injection. The spinal cords of SPD or Lewis rats were contused at the level of T8, using the NYU impactor, as described above. Immediately after SCI the treated groups were injected locally into the injury site or subcutaneously at two adjacent sites in the neck area or intravenously into the tail vein, with DCs in PBS at the concentrations recorded above. Control rats were injected locally or subcutaneously or intravenously, respectively, with the same volume of PBS as the treated rats or locally with non-pulsed DCs.

So that the effect of delayed treatment could be examined, rats were anesthetized 12 or $28 \mathrm{~d}$ after SCI, the laminectomized area was exposed, and the injured spinal cord was exposed further by careful separation of the healed tissue over the spinal cord. DCs or PBS then were injected into the spinal cord as described above.

Assessment of recovery from spinal cord contusion. Functional recovery was determined by locomotor hindlimb performance. This was scored with the open-field locomotor rating scale of Basso, Beattie, and Bresnahan (BBB) on a scale of 0 (complete paralysis) to 21 (normal mobility) (Basso et al., 1996; Young, 1996; Hauben et al., 2000a,b, 2001a,b; Jakeman et al., 2000; Ma et al., 2001). Blind scoring ensured that observers were not aware of the treatment received by each rat. Approximately once a week we evaluated the locomotor activities of the trunk, tail, and hindlimbs in an open field by placing the animal for $4 \mathrm{~min}$ in the center of a circular enclosure ( $90 \mathrm{~cm}$ in diameter, $7 \mathrm{~cm}$ wall height) made of molded plastic with a smooth, nonslip floor. Before each evaluation the rat was examined carefully for perineal infection, wounds in the hindlimbs, and tail and foot autophagia.

Animal care. In spinally injured rats the bladder expression was assisted manually twice a day (three times per day during the first $48 \mathrm{hr}$ after injury) until the end of the second week, by which time automatic voidance had been recovered. Rats were monitored carefully for evidence of urinary tract infection or any other sign of systemic disease. During the first week after contusion and in any case of hematuria after that period they received a course of sulfamethoxazole $(400 \mathrm{mg} / \mathrm{ml})$ and trimethoprim ( $8 \mathrm{mg} / \mathrm{ml}$; Resprim, Teva Laboratories, Netanya, Israel), administered orally with a tuberculin syringe ( $0.3 \mathrm{ml}$ of solution per day). Daily inspections included examination of the laminectomy site for evidence of infection and assessment of the hindlimbs for signs of autophagia or pressure.

Histology. At the indicated time points the rats were perfused intracardially with $100 \mathrm{ml}$ of cold $0.1 \mathrm{M} \mathrm{PBS}, \mathrm{pH} 7.4$, at $4^{\circ} \mathrm{C}$ and then with 200 $\mathrm{ml}$ of $4 \%$ paraformaldehyde (prepared in $0.1 \mathrm{M} \mathrm{PBS}, \mathrm{pH} 7.4$, containing glucose $5 \%$ ). Their spinal cords were removed, postfixed overnight in $10 \%$ phosphate-buffered formaldehyde, dehydrated overnight in etha$\mathrm{nol}$, and embedded in a paraffin block. Serial sections $(4 \mu \mathrm{m})$ from each block were stained with hematoxylin and eosin or Luxol fast blue.

Statistical analyses. Behavioral and morphological data were analyzed by two-tailed Student's $t$ tests. Because the open-field motor scores were measured at different times after the injury, they also were analyzed by two-factor repeated measures ANOVA.

Proliferation assay. Three rats from each group were killed $12 \mathrm{~d}$ after injury, and their spleens were excised and pressed through a fine wire mesh. After lysis of red blood cells with ACK lysing buffer (BioSource, Camarillo, $\mathrm{CA}$ ) the splenocytes were washed in PBS and resuspended in proliferation medium containing DMEM supplemented with $2 \mathrm{mM}$ L-glutamine, $5 \times$ $10^{-5} \mathrm{M} \beta$-mercaptoethanol, $1 \mathrm{~mm}$ sodium pyruvate, $100 \mathrm{IU} / \mathrm{ml}$ penicillin, $100 \mu \mathrm{g} / \mathrm{ml}$ streptomycin, nonessential amino acids, and $1 \%$ (v/v) autologous rat serum. Splenocytes were cultured in quadruplicate in flat-bottomed microtiter wells in $100 \mu \mathrm{l}$ of medium $\left(3 \times 10^{6} \mathrm{cells} / \mathrm{ml}\right)$ with concanavalin A (Con A; $1.25 \mu \mathrm{g} / \mathrm{ml})$, MBP 81-99 (10 $\mu \mathrm{g} / \mathrm{ml})$, MBP $68-82(10 \mu \mathrm{g} / \mathrm{ml})$, A91 (10 $\mu \mathrm{g} / \mathrm{ml})$, or myelin oligodendrocyte glycoprotein (MOG) 35-55 (10 $\mu \mathrm{g} /$ $\mathrm{ml}$ ) or without antigen for $72 \mathrm{hr}$ at $37^{\circ} \mathrm{C}, 90 \%$ relative humidity, and $7 \%$ $\mathrm{CO}_{2}$. The proliferative response was determined by measuring the incorpo- ration of $\left[{ }^{3} \mathrm{H}\right]$ thymidine $(1 \mu \mathrm{Ci} /$ well $)$, which was added to each well for the last $16 \mathrm{hr}$ of the $72 \mathrm{hr}$ culture.

Diffusion anisotropy MRI. Rats were killed, and their spinal cords were excised and examined by MRI. Diffusion anisotropy was measured in a Bruker DMX 400 wide-bore spectrometer (Bremen, Germany), using a microscopy probe with a $5 \mathrm{~mm}$ Helmholz coil and actively shielded magnetic field gradients. The observer was blinded to the identities of the rats. Multi-slice echo imaging was performed with nine axial slices, with the central slice positioned at the center of the spinal injury. Images were obtained with an echo time (TE) of $31 \mathrm{msec}$, repetition time (TR) of 2000 $\mathrm{msec}$, diffusion time of $15 \mathrm{msec}$, diffusion gradient duration of $3 \mathrm{msec}$, field of view of $0.6 \mathrm{~cm}$, matrix size of $128 \times 128$ pixels, slice thickness of $0.5 \mathrm{~mm}$, and slice separation of $1.18 \mathrm{~mm}$. Top to bottom images represent axial sections from head to foot. Four diffusion gradient values $(0$, 28,49 , and $71 \mathrm{gm} / \mathrm{cm}$ ) were applied along the read direction (transverse diffusion) or along the slice direction (longitudinal diffusion). Using a linear fit by weighted minimal squares for each pixel, we obtained a transverse (T) and a longitudinal (L) apparent diffusion coefficient map from which an anisotropy ratio matrix was derived. The accumulated anisotropy in each slice was integrated. For each rat the lowest value of the slice anisotropy integral was defined as the lesion site.

Measurement of cyst area. Before longitudinal sectioning of the spinal cord, each rat was perfused intracardially as described above. The spinal cords were removed, post-fixed overnight in $4 \%$ paraformaldehyde (prepared in $0.1 \mathrm{~m}$ PBS, pH 7.4, containing glucose 5\%), rinsed briefly in PBS, and transferred to sucrose $30 \%$ for cryoprotection for at least $3 \mathrm{~d}$. All procedures were performed at $4^{\circ} \mathrm{C}$. A $20 \mathrm{~mm}$ block of the spinal cord, with the injury site in the middle, was excised, embedded in Tissue-Tek (Miles, Elkhart, IN), and placed in liquid nitrogen. The frozen spinal cord blocks were sectioned longitudinally ( $20 \mu \mathrm{m}$ thickness) on a cryostat, collected onto gelatin-coated slides, and dried at room temperature. The sections were treated for 1 min with a solution of $0.3 \%$ Sudan Black B (Merck, Darmstadt, Germany) in $70 \%$ ethanol. If they were overstained, the sections were dipped in fresh $70 \%$ ethanol until staining was satisfactory. The slides were stored in a dry box at $4^{\circ} \mathrm{C}$ pending further analysis. From each spinal cord ( $n=4$ for each group) 50 sections were inspected, of which the 5th, 25th, and 45th sections (representing bilateral and midsagittal areas of interest) were selected for further quantitative analysis. Cyst sizes were determined by semi-automated image analysis. Borders of the spinal cord sections were defined manually, and the number of blank pixels (i.e., with no tissue inside), each $1.8 \times 1.8 \mu \mathrm{m}^{2}$, was determined automatically (Image-Pro Plus program, Media Cybernetics, Silver Spring, MD), yielding the size of the cysts.

\section{Results}

\section{Characterization of the bone marrow-derived DCs}

We first determined the purity of the DC preparation as well as the maturity of the cells. Bone marrow-derived DCs were analyzed by flow cytometry for expression of the costimulatory B7-2 (CD86) and MHC-II molecules on their surface. As shown in Figure $1 A$, most of the cells (94\%) expressed B7-2 and MHC-II on the day they were harvested for injection (day 7 ), whereas on the day that culture was initiated (day 0 ) these DC markers were expressed by only $1.6 \%$ of the cells. Among the other cell types capable of pronounced expression of B7-2 and MHC-II are macrophages and B-cells. We therefore analyzed cultures on day 7 , using flow cytometry, for the expression of ED-1 (a marker of macrophages) and CD45RA (a B-cell marker). The cells were negative for both of these markers (Fig. $1 B$ ). We also inspected the state of maturation of DCs and examined whether the maturation state is affected by exposure to the antigen. RNA was extracted from DCs before and after the cells were pulsed with A91 (a modified MBP peptide 87-99, which is non-encephalitogenic; see Materials and Methods) and was subjected to RT-PCR to detect expression of the cytokines TNF $\alpha$, IL-12, and IL-6, all of which are known to be expressed by mature DCs, but not by semi-mature or immature DCs (Lutz and Schuler, 2002). As 
A
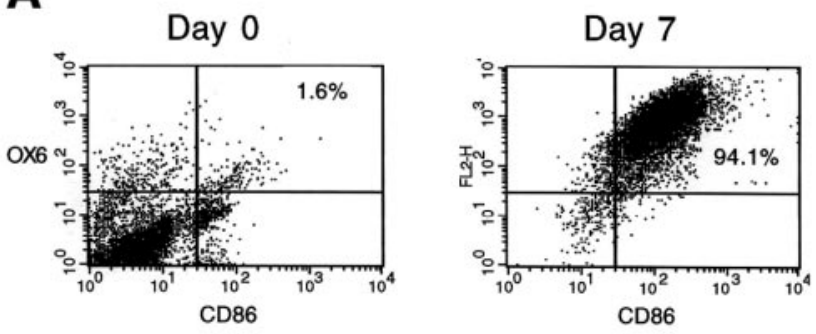

B

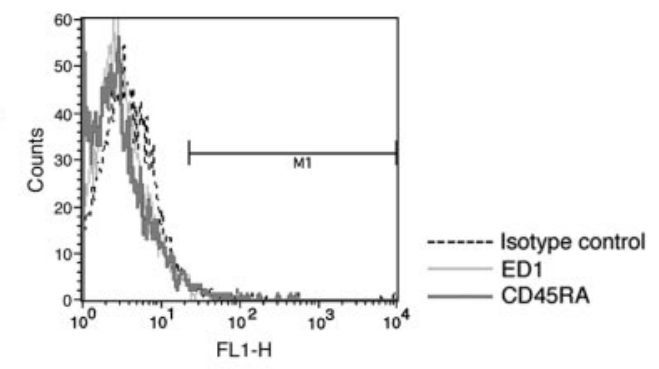

\section{C}

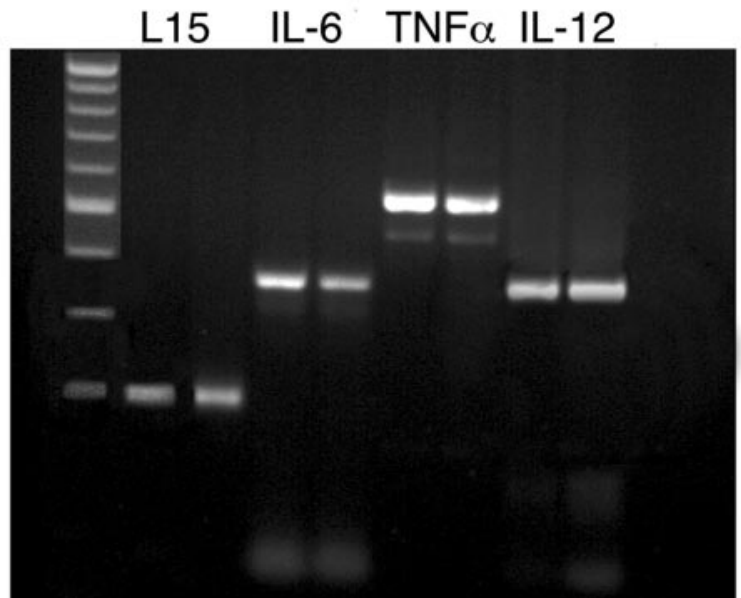

Figure 1. The DCs used in the study are mature. $A$, FACS analysis of rat bone marrow-derived $D C s$ on the first day of culture (day 0 ) and after being cultured for $7 \mathrm{~d}$ in the presence of rmGM-CSF and rmIL-4. Only a few cells (1.6\%) express both B7-2 (CD86) and MHC class II (0X6) molecules on day 0 . Then 7 d later most of the cells ( $94 \%$ ) express large surface numbers of both CD86 and MHC class II molecules. B, FACS analysis of rat bone marrow-derived DCs cultured for $7 \mathrm{~d}$ in the presence of $\mathrm{rmGM}-\mathrm{CSF}$ and $\mathrm{rmIL}-4$. The dashed line shows staining with control $\mathrm{lgG}$ antibodies. Light and dark lines show staining with markers of macrophages (ED-1) and B-cells (CD45RA), respectively. As shown in the histogram, the cells do not express these markers. C, RT-PCR of DCs cultured for $7 \mathrm{~d}$ before and after $2 \mathrm{hr}$ of pulsing with A-91; for each cytokine there are two lanes representing pulsed (right lane) and unpulsed (left lane) DCs. Cultured DCs express IL-6, TNF- $\alpha$, and IL-12, which are markers of mature DCs, both before and after pulsing with A91. The values shown are from one of two experiments with similar results.

shown in Figure 1C, the A91-pulsed DCs expressed all three of these cytokines and therefore were characterized as mature. The same cytokines also were expressed by nonpulsed DCs. It thus seems that the DCs used in the present study are mature and that their maturity was not dependent on pulsing with the antigen.

Local implantation of bone marrow-derived DCs exposed to myelin peptide promotes functional recovery from SCI Male SPD rats ( $n=6$ per group) were subjected to a severe contusive injury as described in Materials and Methods. Rats

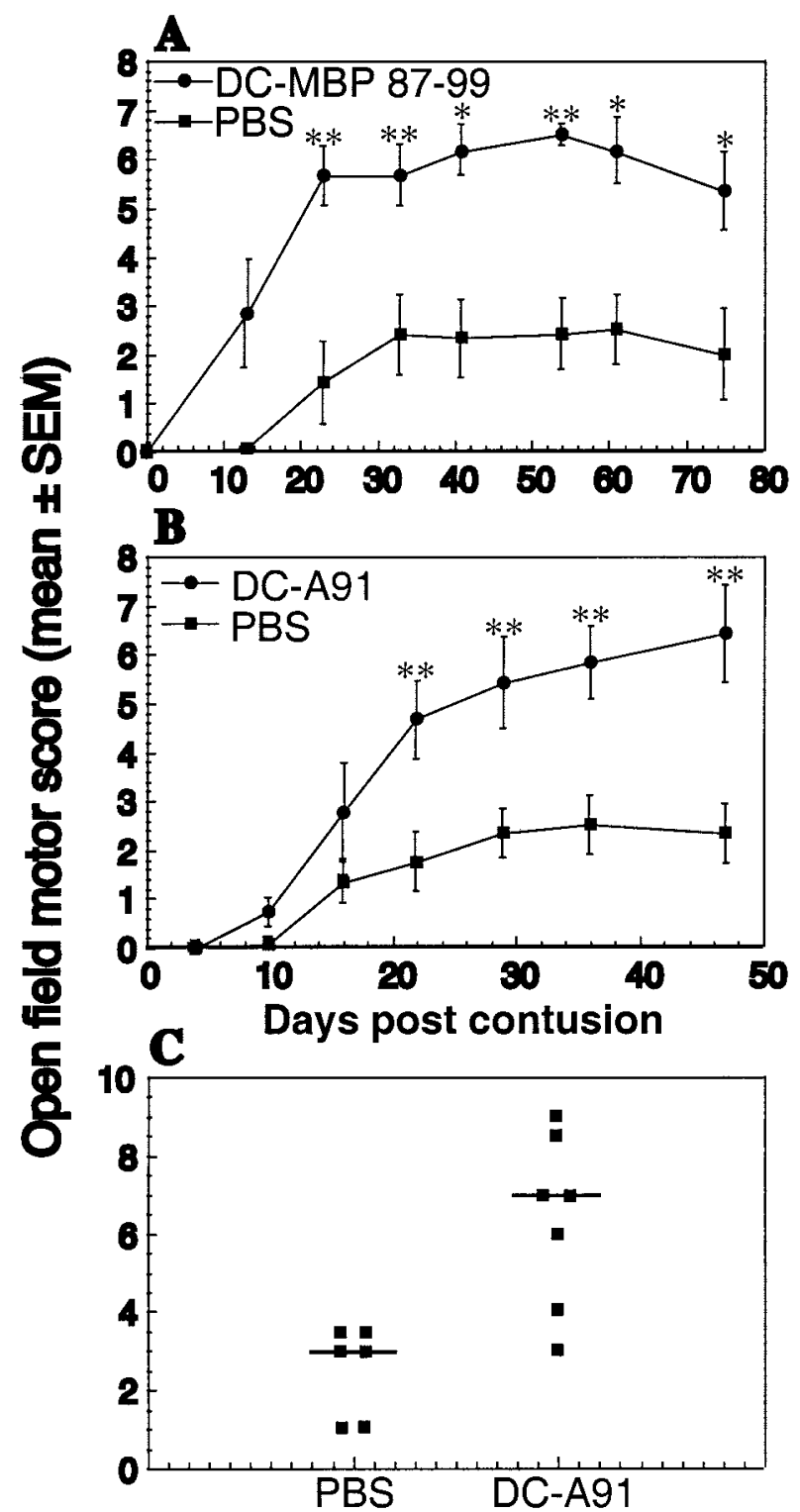

Figure 2. Effect of local injection of bone marrow-derived DCs pulsed with myelin basic peptide 87-99 or with $A 91$ into rats with spinal cord contusion. A, Injection of DCs pulsed with MBP 87-99 (circles) into the injury site immediately after severe spinal cord contusion (NYU impactor; $10 \mathrm{gm}$ weight drop from a height of $50 \mathrm{~mm}$ ) confers significant neuroprotection in male SPD rats ( $n=6$ in each group) as compared with PBS-injected controls. $B, C$, Injection of DCs pulsed with $A 91$ into the site of the lesion $(n=7)$ results in significantly improved locomotor performance. The neuroprotective effect of this treatment was statistically significant $\left({ }^{*} p \leq\right.$ 0.05 and $^{* *} p \leq 0.01$, two-tailed Student's $t$ test; two-factor repeated measures ANOVA, $p \leq$ $0.01 ; \mathrm{df}=1 ; F$ test, 9.658). Note that the scores recorded in ( are those of individual rats at the last time point that was examined.

were treated immediately after the injury by local injection with bone marrow-derived DCs pulsed (by incubation for $2 \mathrm{hr}$ ) with MBP peptide 87-99 or with A91. Control groups were injected locally with the vehicle (PBS). Functional recovery was assessed by the BBB locomotor rating scale on a scale of 0-21 (Basso et al., 1996), where 0 denotes no mobility and 21 denotes full mobility.

After severe contusion and local PBS injection the rats showed extremely limited recovery (Fig. 2). However, injured rats treated with DCs pulsed with either MBP 87-99 peptide (Fig. 2A) or A91 (Fig. $2 B$ ) showed significantly improved recovery, which was detectable as early as $11 \mathrm{~d}$ after contusive SCI (Fig. $1 A, B$ ). Recovery 
A

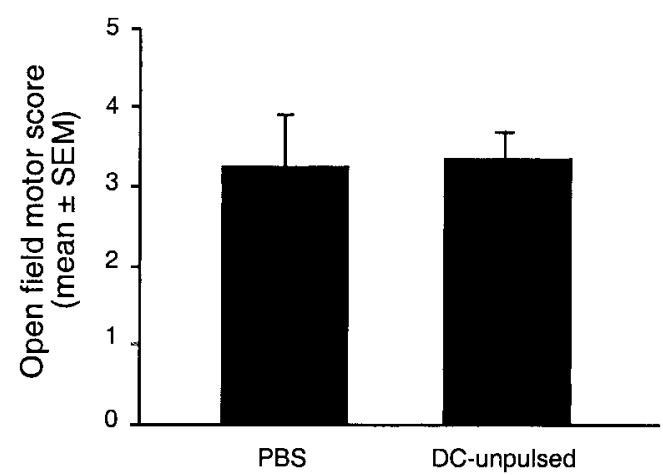

B

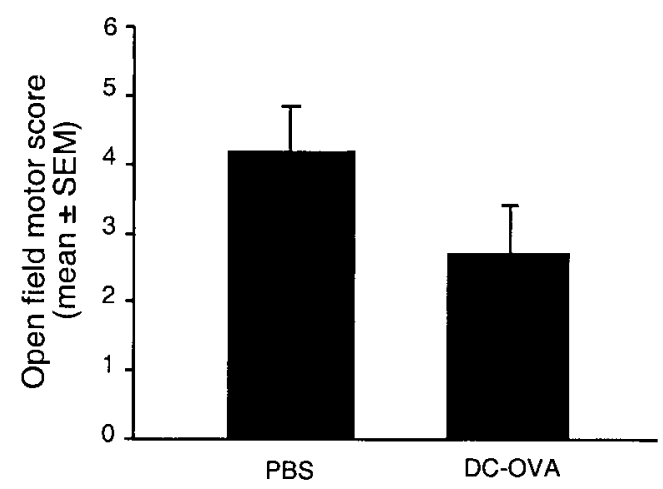

Figure 3. Lack of beneficial effect of local injection of bone marrow-derived DCs, not pulsed or pulsed with an irrelevant peptide, on spinally contused rats. A, Immediately after spinal cord contusion of male SPD rats, nonpulsed DCs derived from bone marrow were injected locally into the site of injury $(n=12)$. Control rats were injected similarly with $\operatorname{PBS}(n=10)$. Bars represent the mean BBB score of each group on reaching a plateau (maximum values). Nonpulsed DCs had no effect on recovery relative to treatment with PBS. Results are pooled data from two experiments in which mean scores for control rats were identical. Four additional experiments showed the same pattern. $B$, Immediately after spinal cord contusion the rats received a local injection of either PBS or bone marrow-derived DCs pulsed with ovalbumin ( 6 male SPD rats in each group). Bars represent the mean $B B B$ score of each group on reaching a plateau (maximal values). There were no significant differences in recovery between the two groups.

was evident in $70-80 \%$ of the treated rats, some of which attained locomotor scores as high as 9 (Fig. 2C), manifested by extensive movement of all three hindlimb joints (BBB score of 7), plantar placement of the paw (BBB of 8), and weight support when stationary (BBB of 9 ). The mean BBB score \pm SEM in the treated rats was $6.4 \pm 0.9$ (Fig. $2 B, C$ ). In control rats the highest $\mathrm{BBB}$ score obtained in this set of experiments was 4 , manifested by slight movements of the hindlimb joints, and the mean score was $2.3 \pm 0.6$. To determine whether antigenic specificity affects the ability of the locally injected DCs to promote spinal cord recovery, we examined the effects of nonpulsed DCs and of DCs pulsed with an irrelevant antigen (ovalbumin) in two separate sets of experiments. The recovery of rats treated with nonpulsed DCs did not differ significantly from that of PBS-treated rats (Fig. 3A) or of rats treated with ovalbumin-pulsed DCs (Fig. 3B).

Histological analysis of rat spinal cords excised 3.5 months after severe spinal contusion and local injection of DCs pulsed with MBP peptide 87-99 or PBS injection revealed significantly better tissue preservation in the DC-treated rats $(n=4)$ than in the controls $(n=4)$, manifested by less cavitation and smaller sites of injury (compare Fig. $4 A, B$ ). Lesion sites in the treated rats were significantly smaller (by two- to threefold) than in the controls. Approximately 50 slices from each spinal cord were inspected, and all showed the same pattern: the cyst areas in the DC-treated spinal cords were smaller than in the untreated spinal cords. Quantification of the cyst areas was measured from three different slices in each spinal cord, representing three planes of sectioning, with the same planes represented in all spinal cords. The mean values of the three slices in the four different animals are shown in Figure 4C. A comparison of the cyst areas revealed significant differences, suggesting that treatment with DCs pulsed with MBP peptide reduces the amount of syringomyelia (central cavitations of the spinal cord).

Differences in the spontaneous recovery from SCI have been reported between rat strains that are susceptible and rat strains that are resistant to the induction of autoimmune disease (Hauben et al., 2001a; Kipnis et al., 2001), as well as between male and female mice or rats (Hauben et al., 2002). It was therefore of interest to examine the effect of the treatment with DCs pulsed with MBP-derived peptide in female Lewis rats, an EAEsusceptible strain. Figure 5 illustrates the significant effect of post-traumatic local injection of A91-pulsed DCs on the functional recovery of six spinally injured female Lewis rats as compared with five PBS-injected female littermates (two-factor repeated measures ANOVA, $p \leq 0.01 ; \mathrm{df}=1 ; F$ test, 8.701). The highest BBB score of the PBS-injected controls was $5.2 \pm 0.2$ (mean \pm SEM), whereas rats injected with A91-pulsed DCs reached a maximum mean score of $7.2 \pm 0.4$ ( $p \leq 0.005$, twotailed Student's $t$ test) (Fig. 5A). At 6 months after SCI the spinal cords of two rats from each group were excised and processed for histological analysis. Approximately 20 sections $(4 \mu \mathrm{m})$ from each spinal cord were inspected. Representative sections from each group are shown in Figure 5, $B$ and $C$. The spinal cords of rats treated with A91-pulsed DCs showed better preservation of neuronal tissue and less cavitation.

\section{An insight into the immunological mechanism underlying the DC-induced recovery from SCI}

To determine whether the observed neuroprotective effect of the treatment with DCs is T-cell-dependent, we injected A91-pulsed DCs locally into spinally injured adult male SPD rats that had been thymectomized at birth and therefore lacked mature T-cells. In the absence of normal T-cell function, A91-pulsed DCs had no significant effect on functional recovery (Fig. 6). The results shown are of one representative experiment of three experiments performed in thymectomized SPD rats. Similar results were obtained in males and females. To compensate for weight variations in the rats used for the different experiments, we always compared BBB scores among groups within the same experiment. The relatively high BBB score in the control group of the experiment with thymectomized rats therefore should not be taken as an indication of the failure of DCs in these rats to promote recovery. The lack of a T-cell-mediated response in thymectomized rats was confirmed by injecting the rats with bovine serum albumin in adjuvant and assessing their ex vivo splenocyte proliferative response to the vaccination (data not shown).

We also examined whether DCs activated by lipopolysaccharide (LPS), a glycolipid component of the cell walls of Gramnegative bacteria that participates in infection-related inflammation (Galanos and Freudenberg, 1993; Ulevitch and Tobias, 1994), would improve functional recovery by inducing a more vigorous immune response. Incubation of DCs with LPS failed to induce a significant beneficial effect. Moreover, DCs pulsed with both LPS and A91 showed the same effect on recovery as DCs 

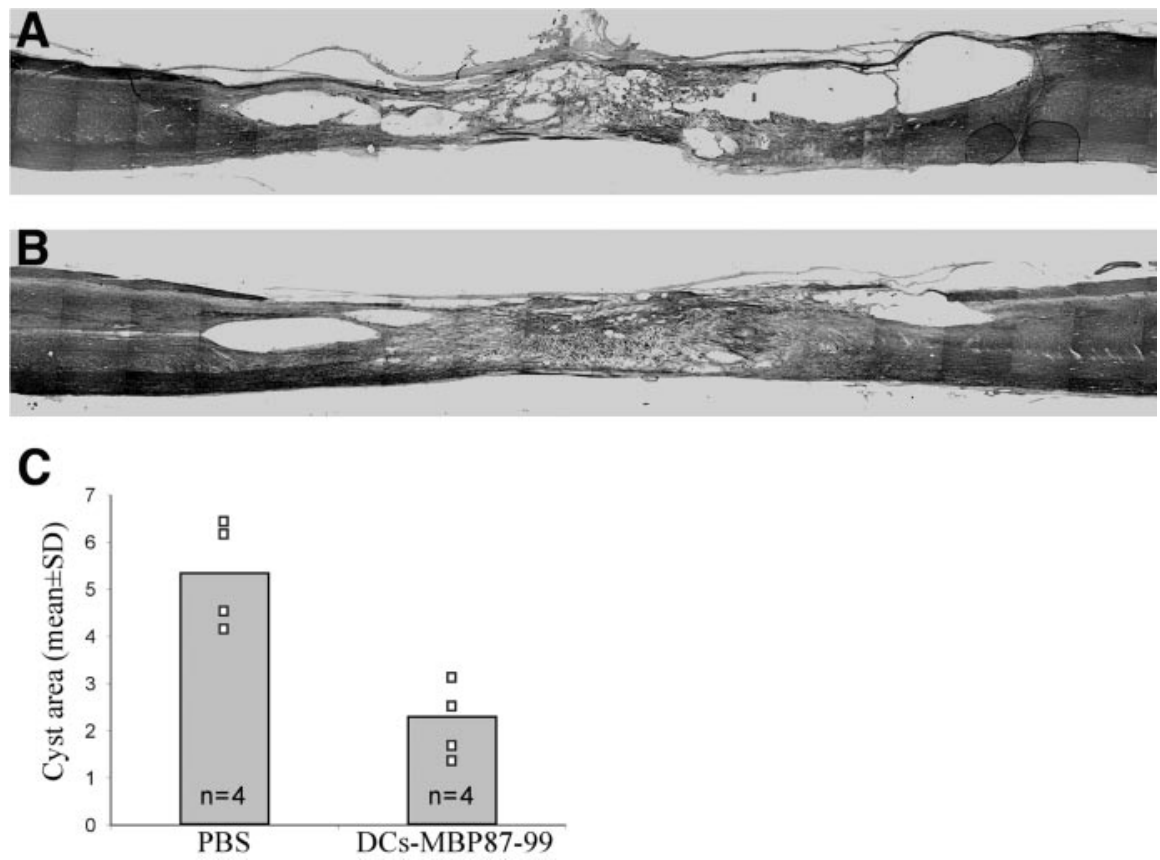

Figure 4. Limited cavity formation after local implantation of DCs pulsed with MBP peptides. Shown are cyst areas in cryosections of spinal cord of vehicle-treated rats $(A)$ and of rats treated with DCs pulsed with MBP peptide ( $B ; n=4$ per group). Cyst areas were measured (Image-Pro Plus) in three slices taken from three planes in four spinal cords in each group ( $C$ ). Cyst areas differed significantly in the different groups ( $p<0.01$, two-tailed Student's $t$ test), suggesting that treatment with DCs pulsed with MBP peptide significantly reduces the amount of syringomyelia (central cavitation of the spinal cord).

pulsed with A91 only (data not shown). These results suggest that the local immune response needed for spinal cord recovery is antigen-specific.

\section{Systemic administration of A91-pulsed DCs promotes functional recovery}

Because the DCs were found to be mature and their mechanism of action T-cell-dependent, it was of interest to determine whether their beneficial effect on recovery could be reproduced by their systemic administration. We first examined whether systemic injection of pulsed DCs can evoke a systemic T-cell response specific to the pulsing antigen. Spinally injured SPD males were injected intravenously with $1 \times 10^{6}$ A91-pulsed DCs or with PBS (Fig. 7). At $10 \mathrm{~d}$ later three rats from each group were killed, their spleens were removed, and splenocyte proliferation was assayed in the presence of different myelin peptides. Figure $7 \mathrm{~A}$ depicts the proliferation of splenocytes in the presence of each of the tested peptides (A91, MBP 81-99, and MBP 68-82) relative to their proliferation in the presence of a control myelin-derived peptide MOG 35-55. Splenocytes from rats injected intravenously with A91-pulsed DCs, but not from rats injected with PBS, displayed a significantly stronger T-cell response to the MBP peptides than to the MOG peptide. These results suggest that systemic administration of $1 \times 10^{6}$ DCs pulsed with A91 evokes a T-cell response to the directly related MBP peptide A91 as well as to other MBP-derived peptides such as $81-99$ and, possibly via a mechanism of epitope spreading, also to MBP 68-82 (Wildbaum et al., 2002).

These findings encouraged us to examine the effect of this systemic route of administration on the functional recovery of spinally injured rats. Male SPD rats were subjected to SCI and immediately afterward received A91-pulsed DCs by intravenous injection. Starting $15 \mathrm{~d}$ after the injury, a significant effect on recovery was observed at all time points that were tested (Fig. $7 B, C$ ). The highest score attained by any rat was 9.5 , which was not significantly higher than that of rats injected via other routes; however, the number of rats that recovered after intravenous injection was higher than that observed after treatment via other routes. Interestingly, in spinally injured SPD rats the administration of A91-pulsed DCs $(2 \times$ $10^{6}$ cells/rat) by subcutaneous injection also led to significantly better recovery than that obtained in PBS-injected matched controls (two-factor repeated measures ANOVA, $p \leq 0.01 ; \mathrm{df}=1 ; F$ test, 12.353; Fig. 8). Note that the SPD rats used in this experiment were females, and therefore their spontaneous recovery was better than that of males (Fig. 8).

\section{Therapeutic window of dendritic} vaccination after spinal cord contusion To examine the effect of delayed local injection of A91-pulsed DCs, 20 SPD male rats underwent severe spinal cord contusion, and their BBB locomotor scores were monitored during the first $10 \mathrm{~d}$ after injury. On day 11 , the 12 rats with the lowest BBB scores were assigned randomly to two groups for which the mean BBB scores \pm SEM were similar $(1.0 \pm 0.4$ in group 1 and $0.9 \pm 0.25$ in group 2 ; $p \leq 0.87$, two-tailed Student's $t$ test). At $1 \mathrm{~d}$ later ( $12 \mathrm{~d}$ after SCI) the lesion site was injected with $5 \times 10^{5}$ A91-pulsed DCs in one group of rats and with nonpulsed DCs in the other. Starting from day 29 after injury, locomotor (BBB) scores in the two groups of rats were found to differ significantly ( $p \leq 0.05$, two-tailed Student's $t$ test; Fig. $9 A, B)$. The overall effect of the delayed treatment with A91-pulsed DCs on functional recovery was statistically significant (two-factor repeated measures ANOVA, $p \leq 0.05$; $\mathrm{df}=$ $1 ; F$ test, 6.206). When this experimental paradigm was repeated, with local administration of A91-pulsed DCs performed $28 \mathrm{~d}$ after the injury, the DCs had no significant effect on locomotor recovery (Fig. 9C,D).

\section{Morphological evidence of improved preservation of neural} tissue after vaccination with DCs pulsed with MBP peptide At 9 months after contusive SCI that was followed immediately by local injection of A91-pulsed DCs or PBS into the site of injury, a spinal cord segment $(\sim 3 \mathrm{~cm}$, with the site of injury in the middle) was excised from two dead male SPD rats in each group and scanned by diffusion-weighted MRI (DW-MRI). Virtual slices of $0.5 \mathrm{~mm}$ were analyzed at intervals of $1.18 \mathrm{~mm}$. The acquired axial images were analyzed to yield the apparent diffusion coefficient values both parallel to and perpendicular to the spinal cord axis. These values were used to derive the value of anisotropy of the tissue, as a marker of white matter integrity (Nevo et al., 2001). The axial anisotropy maps derived from the DW-MRI images present consecutive areas of diffusion anisotropy along the excised cord. In the maps of the group that was treated with A91-pulsed DCs, the area of anisotropy is wider than in the PBS-treated controls (Fig. 10A). In contrast to the continuous longitudinal structure seen in the treated rats, slices taken from the PBS-injected controls showed a loss of organized struc- 

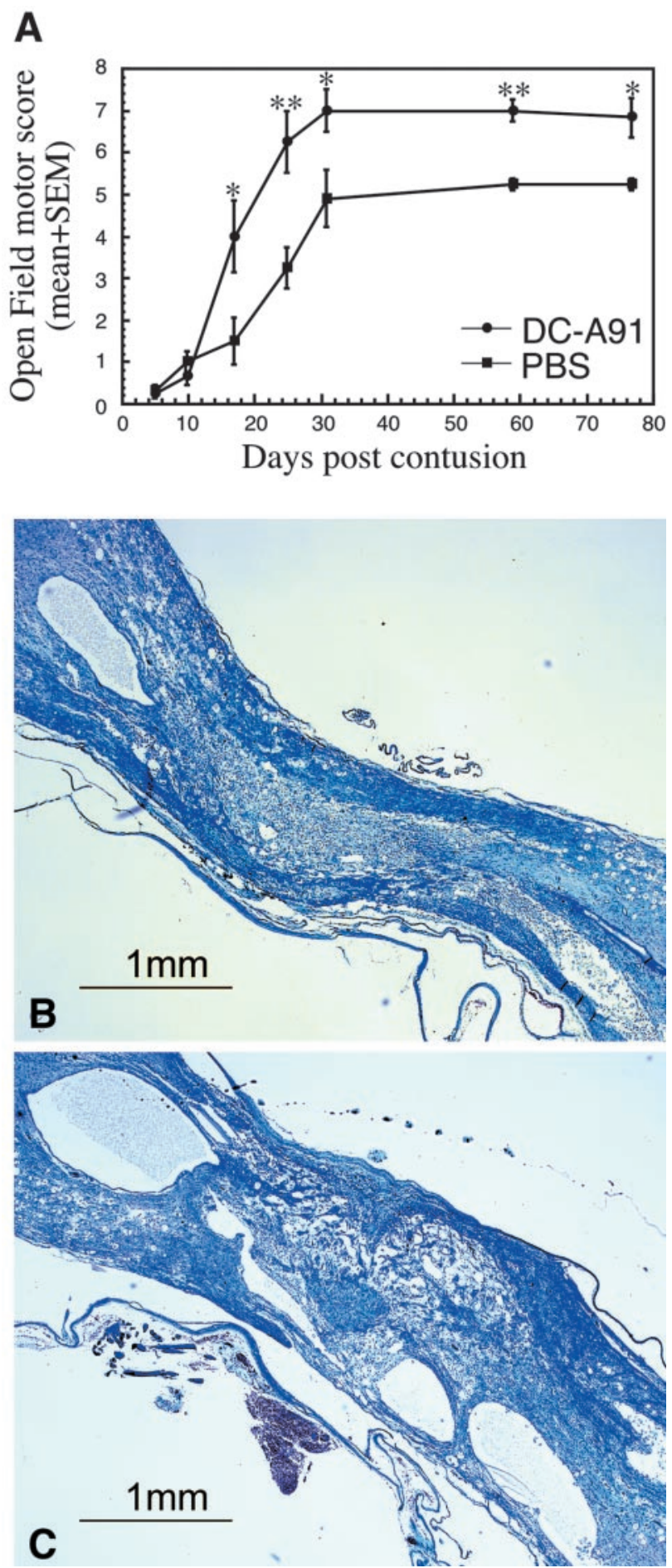

Figure 5. Improved recovery as a result of local treatment with bone marrow-derived DCs pulsed with altered myelin peptide after spinal injury in female Lewis rats. Immediately after severe spinal cord contusion, six female Lewis rats were injected locally with $5 \times 10^{5} \mathrm{~A} 91-$ pulsed DCs, and five matched controls were injected with PBS. A, Injection of A91-pulsed DCs led to a significant improvement in locomotor performance measured by the BBB rating scale $\left({ }^{*} p \leq 0.05\right.$ and ${ }^{* *} p \leq 0.01$, two-tailed Student's $t$ test; two-factor repeated measures ANOVA, $p \leq 0.01 ; \mathrm{df}=1 ;$ F test, 8.701). $B, C$, Photomicrographs of Luxol fast blue-stained spinal cord sections from female Lewis rats treated with A91-pulsed DC cells ( $B)$ or PBS ( () , with BBB scores of 8 or 5 , respectively, 6 months after injury and treatment. These sections are representative of spinal cord sections from two DC-treated and two control rats that were analyzed histologically by Luxol fast blue staining. Note the significantly better preservation of neural tissue and the significantly smaller cysts in the treated rats.

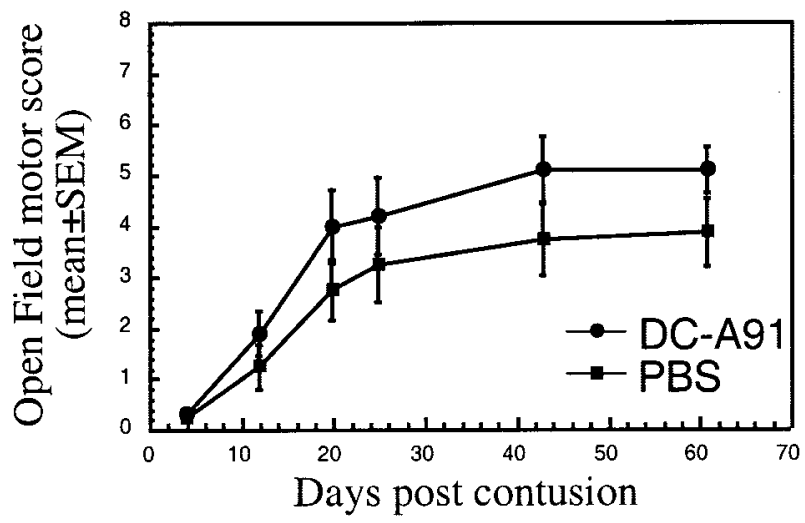

Figure 6. Lack of neuroprotective activity by $D C$ s pulsed with altered myelin peptide in rats deprived of T-cells. At 3 months after undergoing neonatal thymectomy the male SPD rats $(n=$ 5 in each group) were subjected to spinal cord contusion and then were injected locally with $5 \times 10^{5}$ A91-pulsed DCs or with PBS. In the absence of normal T-cell function the DCs had no significant effect on recovery. The results shown are representative of three experiments in thymectomized male and female SPD.

ture at the center of the lesion site, and the area of diffusion anisotropy was relatively small even in slices distant from the site of lesion (Fig. 10 A). Moreover, quantitative analysis showed that the sum of anisotropy (SAI), representing the integrated anisotropy value, was higher in the rats treated with A91-pulsed DCs than in the controls throughout the entire length of scanned segments (Fig. 10B). The behavioral outcome correlated well with the MRI results: the higher the behavioral score, the larger the area of diffusion anisotropy found at the site of the lesion (Hauben et al., 2000b).

\section{Discussion}

The results of this study show a significant improvement in locomotor function after contusive SCI in rats treated by local or systemic injection of bone marrow-derived DCs pulsed in vitro with MBP-derived or related peptides. The beneficial effect of the treatment was also evident morphologically, with better preservation of neural tissue seen on histological examination and a decrease in the size of cavities in the spinal cords of treated rats examined by MRI.

Contrary to the prevailing assumption, DCs were found to populate specific areas of the CNS, including the meninges and choroid plexus (McMenamin, 1999). This presumably enables DCs to "sample" the CNS environment and present CNS antigens in the lymph nodes. In other organs and tissues the DCs under physiological conditions present self-antigens in the context of MHC but lack the costimulatory capacity to initiate a response against them. This well may hold true also for CNS antigens and might contribute to the maintenance of peripheral tolerance to CNS-associated self-antigens. Under pathological conditions, for example after injury to cells, DCs undergo a process of maturation that enables them to present tissue-derived antigens to T-lymphocytes in a highly efficient and stimulatory way. After ischemic injury to the CNS in mature rats the DCs accumulate at the lesion site (Kostulas et al., 2002), and contusive SCI in rats is followed by upregulated expression of chemoattractants of DCs (McTigue et al., 1998). Our group has shown that stimulation of an adaptive immune response against CNS selfantigens after an injury is a normal part of the body's own healing mechanism (Yoles et al., 2001) and a central feature of a proposed new concept of "protective autoimmunity" (Moalem et al., 1999; Schwartz et al., 1999). 
$\mathbf{A}$

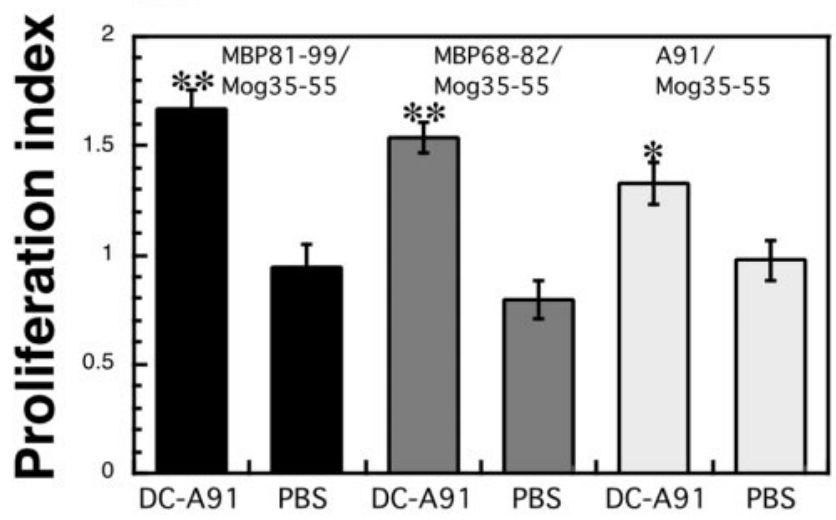

B

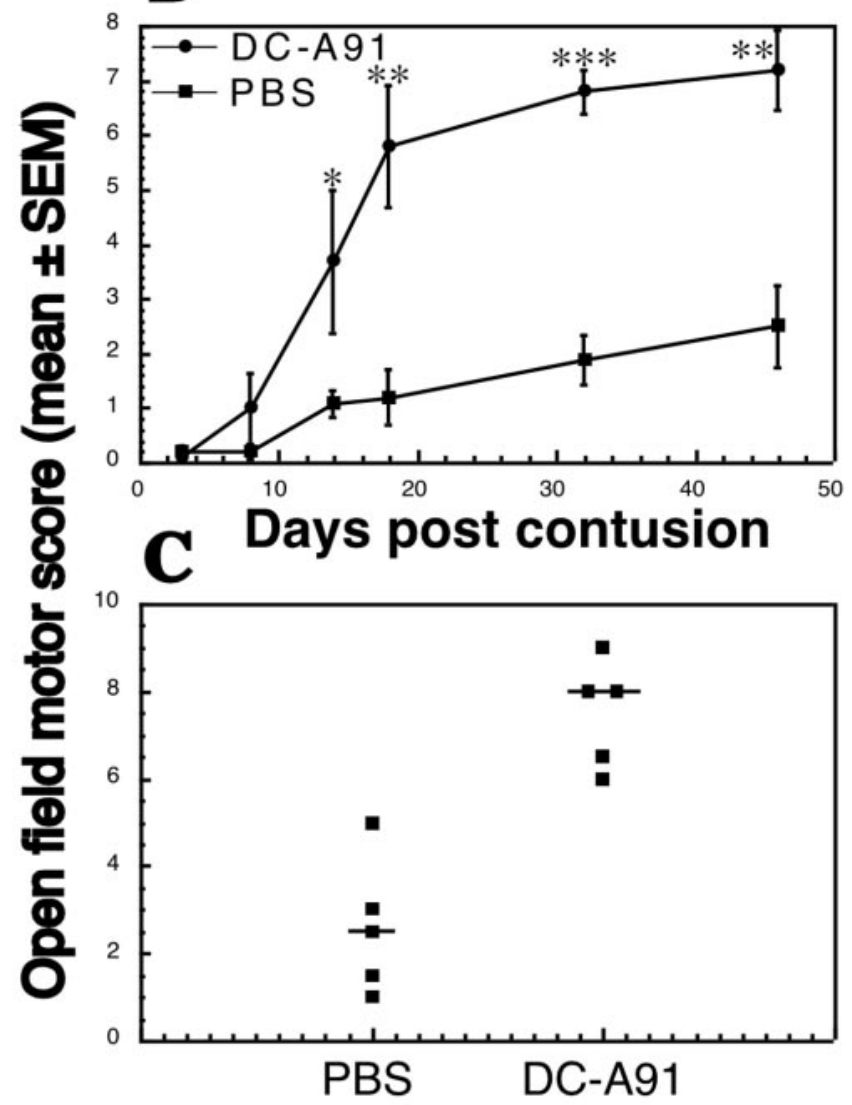

Figure 7. Intravenous administration of A91-pulsed DCs promotes functional recovery after SCI. Sixteen SPD male rats were subjected to severe contusive SCl and were injected intravenously with $1 \times 10^{6}$ A91-pulsed DCs or with PBS. A, At $10 \mathrm{~d}$ later three rats from each group were killed, their spleens were removed, and T-cell proliferation was assayed. Splenocytes from rats injected with DCs pulsed with A91, but not from PBS-injected rats, displayed a significantly stronger T-cell response to MBP peptides (MBP 81-99, MBP 68 - 82, and A91) than to MOG 35-55, suggesting that injection of A91-pulsed DCs induces a T-cell response directed to related myelin antigens. $B$, Intravenous injection of DCs pulsed with $A 91$ resulted in significantly better functional recovery than that obtained after intravenous injection of PBS $\left(n=5\right.$ in each group; ${ }^{*} p \leq 0.05 ;{ }^{* *} p \leq 0.01 ;{ }^{* * *} p \leq 0.001$; two-tailed Student's t test; two-factor repeated measures ANOVA, $p \leq 0.003 ; \mathrm{df}=1 ;$; Ftest, 18.43). C, Scores of individual rats at the last time point that was examined.

The endogenous autoimmune response, although apparently sufficient for day-to-day maintenance (Schwartz and Kipnis, 2002; Nevo et al., 2003), seems to be insufficient to arrest the secondary degeneration accompanying CNS trauma; it can, how-

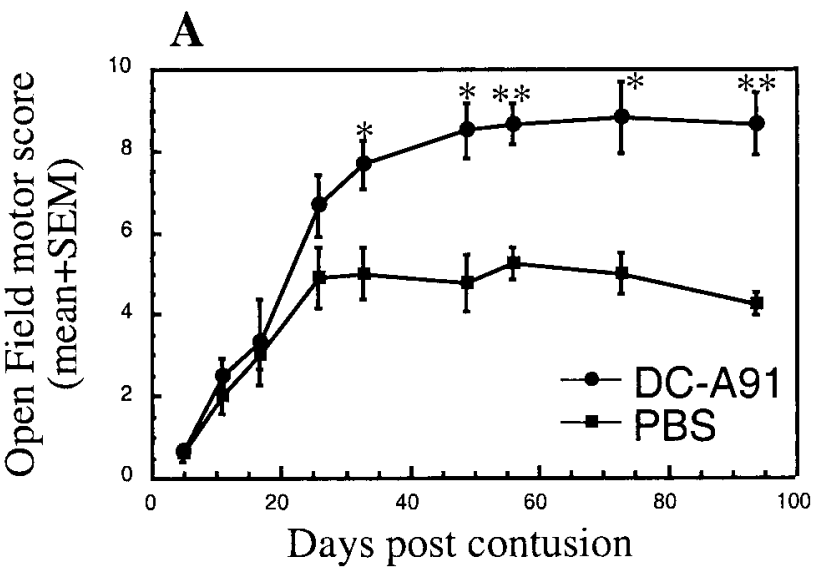

Figure 8. Subcutaneous administration of A91-pulsed DCs promotes functional recovery from SCl. Immediately after severe contusive SCI, female SPD rats ( $n=3$ and 4) were injected subcutaneously with $2 \times 10^{6}$ A91-pulsed DCs or with PBS. The DC-A91-treated rats displayed significantly better locomotor performance than the control $\left({ }^{*} p \leq 0.05\right.$ and ${ }^{* *} p \leq 0.01$, two-tailed Student's $t$ test; two-factor repeated measures ANOVA, $p \leq 0.01 ; \mathrm{df}=1 ; F$ test, 12.353).

ever, be boosted by innate and adaptive immune manipulations (Moalem et al., 1999; Hauben et al., 2000b; Fisher et al., 2001). DCs have been shown to initiate specific immune responses. Such manipulations have been used to evoke immune responses to tumor-associated antigens and currently are undergoing clinical testing for the treatment of cancer (Lau et al., 2001).

A number of studies have shown that DCs can induce immunological tolerance and prevent the development of EAE. The DCs used in all of those studies were probably immature or semimature (Lutz and Schuler, 2002). By using surface markers and specific cytokines, we showed that the DCs used in the present work were mature. Moreover, induction of tolerance by our DCs was ruled out by the observation that the ex vivo proliferation of splenocytes from rats treated with DCs pulsed with MBP-related peptides was enhanced in response to MBP peptides. This conclusion is in line with recent results from our laboratory demonstrating that the outcome of CNS injury in rats is worsened if the animals were neonatally tolerant to myelin-associated antigens or if they received regulatory $\mathrm{CD} 4{ }^{+} \mathrm{CD} 25^{+} \mathrm{T}$-cells that suppress the ability to manifest an immune response (Kipnis et al., 2002; Schwartz and Kipnis, 2002).

Despite the ability of DCs to stimulate an effective immune response, immune activation by DCs pulsed with specific encephalitogenic self-antigens in normal rats or mice has never, to our knowledge, been shown to induce EAE. In one study EAE was induced in irradiated mice by the administration of DCs, but only when CD4 ${ }^{+} \mathrm{T}$-cells specific to an encephalitogenic peptide of $\mathrm{MBP}$ were administered at the same time (Dittel et al., 1999). In our laboratory no symptoms of EAE were observed after the antigen-pulsed DCs that improved recovery from SCI in this study were injected locally (in the spinal cord), subcutaneously, or intravenously into naive rats (data not presented). Treatment with DCs in this way thus appears to be safe, insofar as it evokes a desired immune response while avoiding destructive autoimmunity.

The present study was conducted in two rat strains, SPD and Lewis, that differ in their resistance to EAE and in their ability to withstand CNS trauma (Kipnis et al., 2001). In both strains the treatment with antigen-pulsed DCs was effective. In the Lewis strain we used female rats in which spontaneous recovery (mea- 
sured by the BBB score) is evidently superior to that in male rats (Stein, 2001; Hauben et al., 2002). Nevertheless, DC treatment was still effective in the females, suggesting that the female endogenous response counteracts some, but not all, of the injury-induced degeneration.

We show here that recovery from SCI is improved even if the DC injection is delayed for as long as $12 \mathrm{~d}$ after the injury. The locomotor activity of the rats used in that experiment was assessed before treatment, and only rats with a BBB score lower than 2 were used. This homogeneous group of rats was divided randomly into two groups, one of which was treated with the DCs; the other served as a control. This approach minimizes variations in insult severity among contused rats within the same group and between treated and nontreated groups. Interestingly, only a slight improvement was seen in the control group, whereas the outcome in the treated rats was almost as good as if they had been treated immediately after the injury. This finding might suggest that the mechanisms underlying functional recovery in DC-treated rats involve both neuroprotection and sprouting. Neuroprotection is limited by its operation only during the time period in which axons have not yet degenerated, whereas sprouting may make a significant contribution later. The relatively wide therapeutic time window may be of clinical importance in the treatment of patients with SCI. In consideration of previous findings in connection with regeneration and functional recovery induced by implantation of macrophages into transected spinal cords of rats (Rapalino et al., 1998) and the fact that passive or active immunization with myelin peptides causes local activation of macrophages and microglia (Butovsky et al., 2001), the possibility remains that DC injection, in addition to its neuroprotective effect on uninjured axons, causes sprouting and regeneration of injured axons.

Treatment with nonpulsed DCs or with DCs pulsed with the irrelevant protein ovalbumin had no effect on the injured spinal cord. DCs pulsed with MBP peptide or the altered MBP peptide A91 were beneficial, indicating that mature DCs act as antigenpresenting cells and therefore can be active in spinally injured rats only when administered in conjunction with the relevant CNS antigen. It was proposed recently by our group that different tissues, when under stress, recruit the immune system via different tissue-specific antigens (Mizrahi et al., 2002). Thus injury to myelinated axons (such as spinal cord or optic nerve) can benefit from vaccination with different myelin-associated CNS antigens such as MBP (Moalem et al., 1999; Hauben et al., 2000b), Nogo (Hauben et al., 2001b), and MOG-derived peptides (in mice) (Fisher et al., 2001). In contrast, direct injury of retinal ganglion cells (RGCs), caused, for example, by intravitreal injection of a toxic dose of glutamate, can benefit from vaccination with antigens residing in the retina [such as peptides of interphotoreceptor retinoid-binding protein (IRBP)] (Mizrahiet al., 2002). Thus the specificity of the antigen participating in neuroprotection is determined by the site and not the type of injury and basically is
B

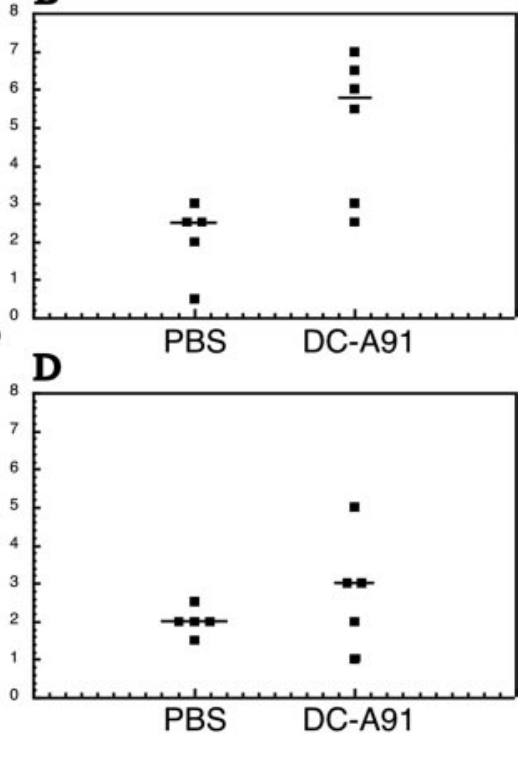

Figure 9. A therapeutic window of $12 \mathrm{~d}$ for injection of $D C$ s pulsed with myelin peptides. A delay of $12 \mathrm{~d}$ in injecting rats 0.01 , thailed Student's $t$ test). The overall effect of the injection with DCs pulsed with myelin peptide was significant when (6) examined. C, D, Using a similar experimental protocol, we administered $5 \times 10^{5} \mathrm{~A} 91$-pulsed DCs $(n=$ 6) or $5 \times 10^{5} \mathrm{DCs}(n=5)$ locally into the injury site of spinally injured male SPD rats $28 \mathrm{~d}$ after SCI. No significant difference in recovery of the two groups was observed.

needed to direct the homing of immune cells to the site in need of their help. In the present study we substituted A91 for natural peptides of MBP because the altered peptide, although as effective as MBP as a vaccine for SCI, is not encephalitogenic (Hauben et al., 2001b). There was no difference in phenotype between pulsed and nonpulsed DCs, as indicated by the identical expression of cytokines in both. It should be borne in mind that both the pulsed DCs and the control nonpulsed DCs were exposed to many other irrelevant proteins during their growth in a serum-rich medium ( $10 \%$ fetal calf serum) as well as in the last few hours of pulsing when the specific peptide was added. These facts lend even more support to the contention that the treatment is antigen-specific. Moreover, stimulation of the DCs with LPS, a strong proinflammatory compound, could not substitute for antigen-specific pulsing.

Several findings in the present study suggest that the effect of DCs on the injured spinal cord is mediated via systemic immune mechanisms. First, there were no significant differences among the effects of DCs administered locally, subcutaneously, or intravenously to the spinal cord. Second, splenocytes from treated rats, when stimulated ex vivo with different antigens, showed a stronger proliferative response to myelin peptides than did splenocytes from untreated rats. This clearly indicates that the DCs administered to the contused rats evoked a systemic immune response to myelin peptides. The DCs administered in that experiment were pulsed with the altered myelin peptide A91 (the peptide used for pulsing of DCs in the behavioral experiments) and probably evoked a response to the ex vivo-tested dominant myelin peptides because of antigenic similarity and epitope spreading. Third, when they were injected into rats that were 
A
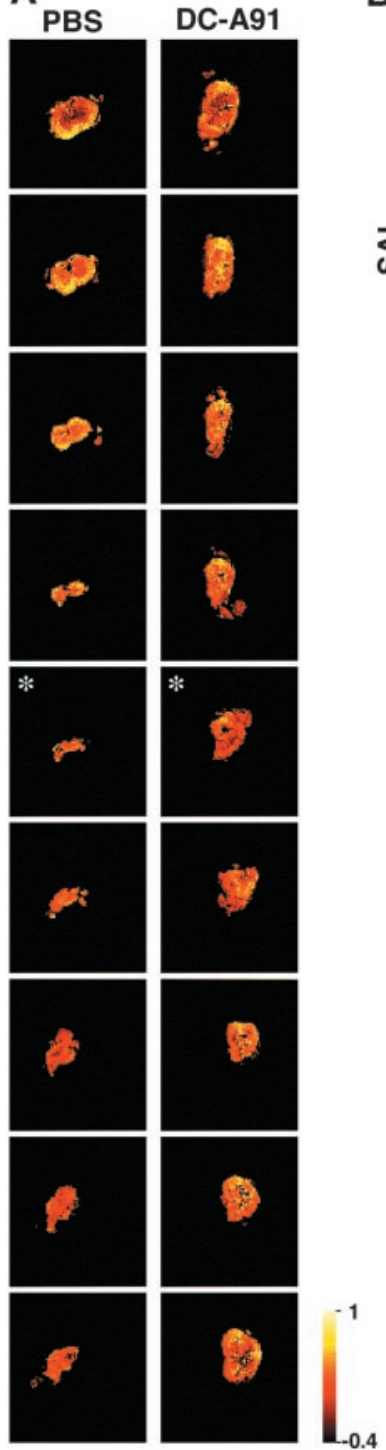

Figure 10. Maps showing diffusion anisotropy of the contused spinal cords. At 9 months after $S C I$ the spinal cords were excised, fixed, and placed in $5 \mathrm{~mm}$ NMR (nuclear magnetic resonance) tubes. $A$, Representative maps of contused spinal cords of rats that were injected locally with A91-pulsed DCs and control rats. Slices from top to bottom correspond to rostral-to-caudal axial slices. Colors correspond to anisotropy values in which bright and dark colors correspond to high and low values of anisotropy to molecular displacement, respectively. Note that the anisotropy value, in the case of the spinal cord, is correlated with white matter integrity. Anisotropy values in the panel are in the range of -0.4 to -1.0 (arbitrary units). The center of the injury site (asterisk) was determined by the slice with the lowest anisotropy value. $B$, Spatial distribution of the SAl value across slices. The panel shows the results for one representative rat of two in each group. Locomotor scores were 8.5 for the treated rat and 1.0 for the control.

thymectomized at birth, DCs had no effect on recovery from contusive SCI. Neonatally thymectomized rats are devoid of mature T-lymphocytes (which normally develop in the thymus of the newborn), indicating that the beneficial effect of DCs on spinal cord recovery is at least partly dependent on T-cells. The injected DCs thus evoke a systemic, antigen-specific, T-celldependent immune response.

Although, as mentioned above, different routes of DC administration did not affect significantly the maximal recovery that was achieved, a high BBB score was achieved by more rats when the treatment was administered intravenously. This might reflect the uniformity of intravenous treatment relative to the subcutaneous or local administration of DCs. It is reasonable to assume that the intravenously injected DCs reach the spleen and other lymphoid organs. Intravenously injected mature DCs have been shown to reach the spleen within $1 \mathrm{~d}$ of injection and to localize preferentially in the T-cell area of the spleen (Sai et al., 2002). The intravenous route for DC administration is known to be effective both for induction of immune tolerance (Menges et al., 2002) and for induction of immune activation (Fong et al., 2001; Lau et al., 2001; Sai et al., 2002).

Our results lead us to assume that the mechanism by which DCs influence recovery from SCI is similar to that of vaccination with myelin-associated peptides. This similarity is evident not only immunologically but also morphologically, with better preservation of neural tissue evaluated histologically and decreased cavity size on MRI (Hauben et al., 2000b; Butovsky et al., 2001; Nevo et al., 2001). The local mechanisms of protection acting on the neural tissue are not understood fully, but accumulating data support a key role for resident microglia and infiltrating macrophages in this process. Several years ago our group showed that local implantation of activated macrophages into completely transected spinal cords leads to regeneration of severed axons with partial functional recovery of otherwise completely paralyzed rats (Rapalino et al., 1998). The injected activated macrophages are reminiscent of antigen-presenting cells (Bomstein et al., 2003). Vaccination with myelin peptides or transfer of $\mathrm{T}$-cells reactive to these peptides, both shown to be neuroprotective, recently was found to cause local activation of microglia at the site of the injured spinal cord as well as upregulation of MHC-II and B7-2 costimulatory molecules (Butovsky et al., 2001). Examination of the local inflammatory response by immunohistochemical analysis of the contused spinal cord showed that better outcome of injury was correlated with an early rise in the numbers of activated microglia/macrophages. Activated macrophages/microglia can clear the injured tissue of debris, buffer toxic compounds, and secrete neurotrophic factors. Studies in vitro showed that some of these activities are enhanced after stimulation by T-cells (I. Shaked, O. Butovsky, T. Mizrahi, R. Gersner, S. Mordechai, X. Xiao, P. Soteropoulos, P. Tolias, R. P. Hart, and M. Schwartz, unpublished observations).

The results of this study clearly show a beneficial effect of DCs pulsed with specific antigens on recovery of rats from SCI. We conclude that the effect of DCs is systemic and T-cell-dependent and that, similarly to vaccination with myelin peptides, it evokes an adaptive immune response directed to peptides of MBP. Our treatment therefore can be viewed as a DC vaccination and, like vaccination with the peptide in adjuvant, is a means of helping 
the local innate response to cope with stressful injury-induced conditions by promoting the body's own self-repair mechanism, namely the adaptive systemic immune response against antigens residing in the lesion site.

\section{References}

Basso DM, Beattie MS, Bresnahan JC (1996) Graded histological and locomotor outcomes after spinal cord contusion using the NYU weight-drop device versus transection. Exp Neurol 139:244-256.

Bavetta S, Hamlyn PJ, Burnstock G, Lieberman AR, Anderson PN (1999) The effects of FK506 on dorsal column axons following spinal cord injury in adult rats: neuroprotection and local regeneration. Exp Neurol 158:382-393.

Bazan NG, Rodriguez de Turco EB, Allan G (1995) Mediators of injury in neurotrauma: intracellular signal transduction and gene expression. J Neurotrauma 12:791-814.

Beattie MS, Bresnahan JC, Komon J, Tovar CA, Van Meter M, Anderson DK, Faden AI, Hsu CY, Noble LJ, Salzman S, Young W (1997) Endogenous repair after spinal cord contusion injuries in the rat. Exp Neurol 148:453-463.

Behrmann DL, Bresnahan JC, Beattie MS (1994) Modeling of acute spinal cord injury in the rat: neuroprotection and enhanced recovery with methylprednisolone, U-74006F and YM-14673. Exp Neurol 126:61-75.

Bethea JR, Nagashima H, Acosta MC, Briceno C, Gomez F, Marcillo AE, Loor K, Green J, Dietrich WD (1999) Systemically administered interleukin-10 reduces tumor necrosis factor- $\alpha$ production and significantly improves functional recovery following traumatic spinal cord injury in rats. J Neurotrauma 16:851-863.

Blesch A, Tuszynski MH (1997) Robust growth of chronically injured spinal cord axons induced by grafts of genetically modified NGF-secreting cells. Exp Neurol 148:444-452.

Bomstein Y, Marder JB, Vitner K, Smirnov I, Lisaey G, Butovsky O, Fulga V, Yoles E (2003) Features of skin-coincubated macrophages that promote recovery from spinal cord injury. J Neuroimmunol, in press.

Bregman BS (1998) Regeneration in the spinal cord. Curr Opin Neurobiol 8:800-807.

Brewer KL, Bethea JR, Yezierski RP (1999) Neuroprotective effects of interleukin-10 following excitotoxic spinal cord injury. Exp Neurol 159:484-493.

Butovsky O, Hauben E, Schwartz M (2001) Morphological aspects of spinal cord autoimmune neuroprotection: colocalization of T cells with B7-2 (CD86) and prevention of cyst formation. FASEB J 15:1065-1067.

Constantini S, Young W (1994) The effects of methylprednisolone and the ganglioside GM1 on acute spinal cord injury in rats. J Neurosurg 80:97-111.

Crowe MJ, Bresnahan JC, Shuman SL, Masters JN, Beattie MS (1997) Apoptosis and delayed degeneration after spinal cord injury in rats and monkeys. Nat Med 3:73-76.

Dittel BN, Visintin I, Merchant RM, Janeway Jr CA (1999) Presentation of the self-antigen myelin basic protein by dendritic cells leads to experimental autoimmune encephalomyelitis. J Immunol 163:32-39.

Faden AI (1993) Experimental neurobiology of central nervous system trauma. Crit Rev Neurobiol 7:175-186.

Fisher J, Levkovitch-Verbin H, Schori H, Yoles E, Butovsky O, Kaye JF, BenNun A, Schwartz M (2001) Vaccination for neuroprotection in the mouse optic nerve: implications for optic neuropathies. J Neurosci $21: 136-142$.

Fong L, Brockstedt D, Benike C, Wu L, Engleman EG (2001) Dendritic cells injected via different routes induce immunity in cancer patients. J Immunol 166:4254-4259.

Franzen R, Schoenen J, Leprince P, Joosten E, Moonen G, Martin D (1998) Effects of macrophage transplantation in the injured adult rat spinal cord: a combined immunocytochemical and biochemical study. J Neurosci Res 51:316-327.

Galanos C, Freudenberg MA (1993) Mechanisms of endotoxin shock and endotoxin hypersensitivity. Immunobiology 187:346-356.

Gaur A, Boehme SA, Chalmers D, Crowe PD, Pahuja A, Ling N, Brocke S, Steinman L, Conlon PJ (1997) Amelioration of relapsing experimental autoimmune encephalomyelitis with altered myelin basic protein peptides involves different cellular mechanisms. J Neuroimmunol 74:149-158.

Hauben E, Nevo U, Yoles E, Moalem G, Agranov E, Mor F, Akselrod S,
Neeman M, Cohen IR, Schwartz M (2000a) Autoimmune T cells as potential neuroprotective therapy for spinal cord injury. Lancet 355:286-287.

Hauben E, Butovsky O, Nevo U, Yoles E, Moalem G, Agranov E, Mor F, Leibowitz-Amit R, Pevsner E, Akselrod S, Neeman M, Cohen IR, Schwartz M (2000b) Passive or active immunization with myelin basic protein promotes recovery from spinal cord contusion. J Neurosci 20:6421-6430.

Hauben E, Agranov E, Gothilf A, Nevo U, Cohen A, Smirnov I, Steinman L, Schwartz M (2001a) Posttraumatic therapeutic vaccination with modified myelin self-antigen prevents complete paralysis while avoiding autoimmune disease. J Clin Invest 108:591-599.

Hauben E, Ibarra A, Mizrahi T, Barouch R, Agranov E, Schwartz M (2001b) Vaccination with a Nogo-A-derived peptide after incomplete spinal cord injury promotes recovery via a T-cell-mediated neuroprotective response: comparison with other myelin antigens. Proc Natl Acad Sci USA 98:15173-15178.

Hauben E, Mizrahi T, Agranov E, Schwartz M (2002) Sexual dimorphism in the spontaneous recovery from spinal cord injury: a gender gap in beneficial autoimmunity? Eur J Neurosci 16:1731-1740.

Jakeman LB, Guan Z, Wei P, Ponnappan R, Dzwonczyk R, Popovich PG, Stokes BT (2000) Traumatic spinal cord injury produced by controlled contusion in mouse. J Neurotrauma 17:299-319.

Kipnis J, Yoles E, Schori H, Hauben E, Shaked I, Schwartz M (2001) Neuronal survival after CNS insult is determined by a genetically encoded autoimmune response. J Neurosci 21:4564-4571.

Kipnis J, Mizrahi T, Hauben E, Shaked I, Shevach E, Schwartz M (2002) Neuroprotective autoimmunity: naturally occurring $\mathrm{CD} 4{ }^{+} \mathrm{CD} 25^{+}$regulatory $\mathrm{T}$ cells suppress the ability to withstand injury to the central nervous system. Proc Natl Acad Sci USA 99:15620-15625.

Knight SC, Burke F, Bedford PA (2002) Dendritic cells, antigen distribution, and the initiation of primary immune responses to self and non-self antigens. Semin Cancer Biol 12:301-308.

Kostulas N, Li HL, Xiao BG, Huang YM, Kostulas V, Link H (2002) Dendritic cells are present in ischemic brain after permanent middle cerebral artery occlusion in the rat. Stroke 33:1129-1134.

Lau R, Wang F, Jeffery G, Marty V, Kuniyoshi J, Bade E, Ryback ME, Weber J (2001) Phase I trial of intravenous peptide-pulsed dendritic cells in patients with metastatic melanoma. J Immunother 24:66-78.

Lazarov-Spiegler O, Solomon AS, Zeev-Brann AB, Hirschberg DL, Lavie V, Schwartz M (1996) Transplantation of activated macrophages overcomes central nervous system regrowth failure. FASEB J 10:1296-1302.

Link H, Huang YM, Masterman T, Xiao BG (2001) Vaccination with autologous dendritic cells: from experimental autoimmune encephalomyelitis to multiple sclerosis. J Neuroimmunol 114:1-7.

Liu D, Yang R, Yan X, McAdoo DJ (1994) Hydroxyl radicals generated in vivo kill neurons in the rat spinal cord: electrophysiological, histological, and neurochemical results. J Neurochem 62:37-44.

Liu YJ (2001) Dendritic cell subsets and lineages, and their functions in innate and adaptive immunity. Cell 106:259-262.

Lutz M, Schuler G (2002) Immature, semi-mature, and fully mature dendritic cells: which signals induce tolerance or immunity? Trends Immunol 23:445.

Lutz MB, Kukutsch N, Ogilvie AL, Rossner S, Koch F, Romani N, Schuler G (1999) An advanced culture method for generating large quantities of highly pure dendritic cells from mouse bone marrow. J Immunol Methods 223:77-92.

Ma M, Basso DM, Walters P, Stokes BT, Jakeman LB (2001) Behavioral and histological outcomes following graded spinal cord contusion injury in the C57Bl/6 mouse. Exp Neurol 169:239-254.

McMenamin PG (1999) Distribution and phenotype of dendritic cells and resident tissue macrophages in the dura mater, leptomeninges, and choroid plexus of the rat brain as demonstrated in wholemount preparations. J Comp Neurol 405:553-562.

McTigue DM, Tani M, Krivacic K, Chernosky A, Kelner GS, Maciejewski D, Maki R, Ransohoff RM, Stokes BT (1998) Selective chemokine mRNA accumulation in the rat spinal cord after contusion injury. J Neurosci Res 53:368-376.

Mellman I, Steinman RM (2001) Dendritic cells: specialized and regulated antigen processing machines. Cell 106:255-258.

Menges M, Rossner S, Voigtlander C, Schindler H, Kukutsch NA, Bogdan C, Erb K, Schuler G, Lutz MB (2002) Repetitive injections of dendritic cells 
matured with tumor necrosis factor $\alpha$ induce antigen-specific protection of mice from autoimmunity. J Exp Med 195:15-21.

Mizrahi T, Hauben E, Schwartz M (2002) The tissue-specific self-pathogen is the protective self-antigen: the case of uveitis. J Immunol 169:5971-5977.

Moalem G, Leibowitz-Amit R, Yoles E, Mor F, Cohen IR, Schwartz M (1999) Autoimmune $\mathrm{T}$ cells protect neurons from secondary degeneration after central nervous system axotomy. Nat Med 5:49-55.

Nevo U, Hauben E, Yoles E, Agranov E, Akselrod S, Schwartz M, Neeman M (2001) Diffusion anisotropy MRI for quantitative assessment of recovery in injured rat spinal cord. Magn Reson Med 45:1-9.

Nevo U, Kipnis J, Golding I, Shaked I, Neumann A, Akselrod S, Schwartz M (2003) Autoimmunity as a special case of immunity: removing threats from within. Trends Mol Med 9:88-93.

Rapalino O, Lazarov-Spiegler O, Agranov E, Velan GJ, Yoles E, Fraidakis M, Solomon A, Gepstein R, Katz A, Belkin M, Hadani M, Schwartz M (1998) Implantation of stimulated homologous macrophages results in partial recovery of paraplegic rats. Nat Med 4:814-821.

Sai T, Milling SW, Mintz B (2002) Freezing and thawing of bone marrowderived murine dendritic cells with subsequent retention of immunophenotype and of antigen processing and presentation characteristics. J Immunol Methods 264:153-162.

Schwartz M, Kipnis J (2002) Autoimmunity on alert: naturally occurring regulatory $\mathrm{CD} 4{ }^{+} \mathrm{CD} 25^{+} \mathrm{T}$ cells as part of the evolutionary compromise between a "need" and a "risk." Trends Immunol 23:530-534.
Schwartz M, Moalem G, Leibowitz-Amit R, Cohen IR (1999) Innate and adaptive immune responses can be beneficial for CNS repair. Trends Neurosci 22:295-299.

Stein DG (2001) Brain damage, sex hormones, and recovery: a new role for progesterone and estrogen? Trends Neurosci 24:386-391.

Talmor M, Mirza A, Turley S, Mellman I, Hoffman LA, Steinman RM (1998) Generation or large numbers of immature and mature dendritic cells from rat bone marrow cultures. Eur J Immunol 28:811-817.

Turley SJ (2002) Dendritic cells: inciting and inhibiting autoimmunity. Curr Opin Immunol 14:765-770.

Ulevitch RJ, Tobias PS (1994) Recognition of endotoxin by cells leading to transmembrane signaling. Curr Opin Immunol 6:125-130.

Wildbaum G, Netzer N, Karin N (2002) Trl cell-dependent active tolerance blunts the pathogenic effects of determinant spreading. J Clin Invest 110:701-710.

Xiao BG, Huang YM, Yang JS, Xu LY, Link H (2001) Bone marrow-derived dendritic cells from experimental allergic encephalomyelitis induce immune tolerance to EAE in Lewis rats. Clin Exp Immunol 125:300-309.

Yoles E, Hauben E, Palgi O, Agranov E, Gothilf A, Cohen A, Kuchroo V, Cohen IR, Weiner H, Schwartz M (2001) Protective autoimmunity is a physiological response to CNS trauma. J Neurosci 21:3740-3748.

Young W (1996) Spinal cord regeneration [comment]. Science 273:451. 